\title{
The Lesser Occipital Nerve in Fetuses
}

\author{
El Nervio Occipital Menor en Fetos
}

P. Pillay; P. Partab; L. Lazarus \& K. S. Satyapal

PILLAY, P.; PARTAB, P.; LAZARUS, L. \& SATYAPAL, K. S. The lesser occipital nerve in fetuses. Int. J. Morphol., 30(1):140-144, 2012.

SUMMARY: The lesser occipital nerve (LON) is an ascending superficial branch of the cervical plexus that has a variable origin either from the ventral ramus of the second cervical nerve or second and third cervical nerves and is purely sensory. Forty fetuses (right side: 40/80; left: 40/80) with gestational ages between 15 to 28 weeks were microdissected to document the anatomy of the LON. Results: a) Incidence and Morphometry: LON present in $100 \%$ specimens, with average length on the right and left sides of $23.59 \pm 2.32$ $\mathrm{mm}$ and $23.45 \pm 2.27 \mathrm{~mm}$, respectively; b) Course: In its ascent towards the occipital region, the LON was located on the splenius capitus muscle in $85 \%$ of specimens and in $15 \%$ of the specimens, it ascended vertically on the sternocleidomastoid muscle towards the ear, innervating its superior third; c) Branching pattern: LON displayed (i) single: 70\%; (ii) duplicate: $26 \%$ and (iii) triplicate: $4 \%$ patterns; d) Variation in the course of LON was observed in $6 \%$ of the specimens. Knowledge of the anatomy and variations of the LON may assist in the understanding of cervicogenic headaches and may be of assistance to anesthetists performing regional anesthesia for surgical procedures in the neck.

KEY WORDS: Lesser occipital nerve; Superficial branch of the cervical plexus; Cervicogenic headaches.

\section{INTRODUCTION}

The cervical plexus is a seen as an intricate formation by the upper four cervical nerves and forms the superficial and deep cervical plexuses. The lesser occipital nerve (LON) is an ascending superficial branch of the cervical plexus that has a variable origin either from the ventral ramus of the second cervical nerve or second and third cervical nerves and is purely sensory (Berry et al., 1995, Pantaloni \& Sullivan, 2000; Madhavi \& Holla, 2004). The LON curves lateral to the accessory nerve, then runs vertically upward along the posterior margin of the sternocleidomastoid muscle (Hollinshead, 1974; Ellis \& Fieldman, 1993). It perforates the deep fascia near the cranium and continues superiorly over the occiput to supply the integument and communicates with the greater occipital nerve medially (Lucas et al., 1994; Tubbs et al., 2007). The area within the posterior triangle superior to the accessory nerve is referred to as the "carefree part" since no significant structures are observed in this area; however Lucus et al., observed an anomalous LON ascending to the occipital area lying in the posterior triangle of the neck. It has been reported that normally a single LON supplies the postero-lateral area of the neck, scalp and the upper third of the auricle; however variations in the form of duplicate and triplicate LONs have also been reported (Romanes, 1987; Lucas et al.; Berry et al.; Bescer et al.;
Madhavi \& Holla). In addition, Madhavi \& Holla observed an anomaly of the LON whereby there was triplication of the LON and this was described as Type I, Type II and Type III. Additionally, in a study conducted by Pantaloni \& Sullivan it was reported that the LON supplied the superior two-thirds of the ear rather than the superior one third as previously described and stressed the importance of this variation in facial rejuvenation surgery (Lucas et al.; Berry et al.). The aim of this study was to document the variations and patterns of the LONs in fetuses.

\section{MATERIAL AND METHOD}

Forty fetuses (gestational age: 15 to 28 weeks) (right side: 40/80; left: 40/80) were obtained from the Department of Clinical Anatomy, University of KwaZulu-Natal in accordance with the National Health Act 61 of 2003 and Human Tissue Act 65 of 1983: Ethical Clearance No: BF 156/07. Fetal cadaveric specimens with signs of injuries, trauma or pathology in the lateral and posterior compartments of the neck were excluded. The detailed dissection of the posterior triangle of the neck was completed using standard 
Carl Ziess Stemi DV4 micro-dissecting instruments, and the anatomical course of the LON, and variations were recorded and photographed using a Canon digital camera. In addition, the LON length was measured using a Wilson Wolpert Digital vernier caliper $(0-150 \mathrm{~mm})$.

\section{RESULTS}

a) Incidence and Morphometry. The LON was present in $100 \%(40 / 40)$ of the specimens with an average length on the right and left sides of $23.59 \pm 2.32(19.55-26.34) \mathrm{mm}$ and $23.45 \pm 2.27$ (19.74-28.76) $\mathrm{mm}$, respectively.

b) Course. The LON is an ascending branch of the superficial cervical plexus. It emerged from beneath the posterior margin of the sternocleidomastoid muscle by piercing the superficial cervical fascia and ascended along the lateral margin of the sternocleidomastoid muscle, curving around the accessory nerve. In its ascent towards the occipital region, the LON was located on the splenius capitus muscle in 68/ $80(85 \%)$ of specimens (Fig. 1) and in $12 / 80(15 \%)$ of the specimens, it ascended vertically on the sternocleidomastoid muscle towards the ear, innervating its superior third.

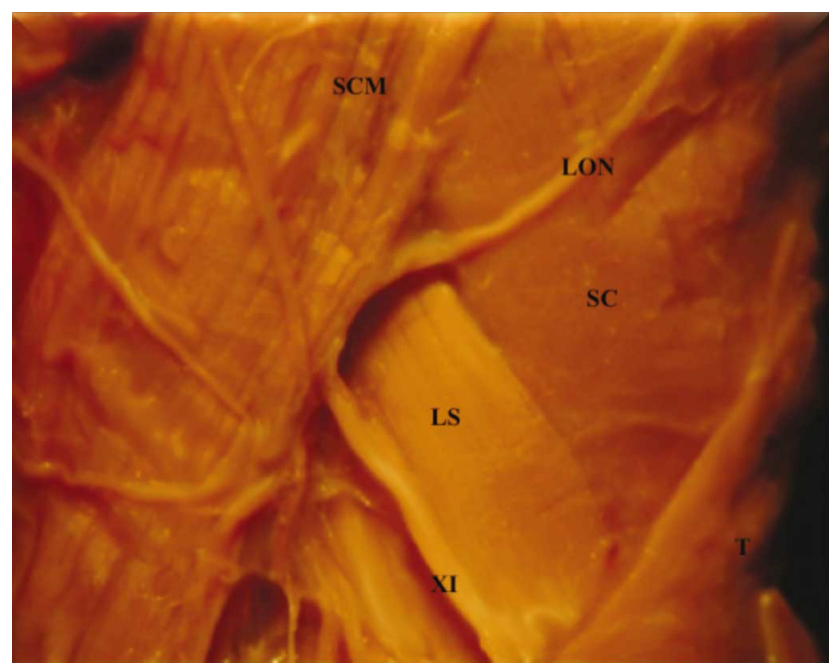

Fig. 1. Left anterior view of the course of the lesser occipital nerve. LON: Lesser Occipital nerve; SC: Splenius capitis; LS: Levator scapulae; XI: Accessory nerve; SCM: Sternocleidoastoid muscle; T: Trapezius muscle

c) Branching patterns. In its ascent, the LON depicted the following branching patterns: (i) single; (ii) duplicate and (iii) triplicate.

Single: The LON emerged as a single trunk from beneath the posterior margin of sternocleidomastoid muscle diverging from the great auricular nerve, curving lateral to the accessory nerve in 56/80 (70\%) of the specimens (Fig. 2).

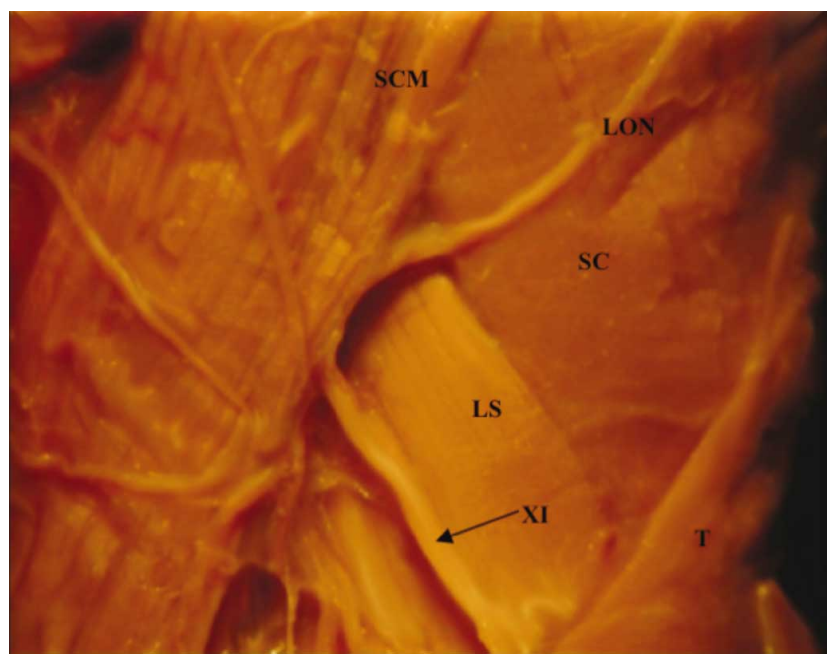

Fig. 2. Left anterior view of the single branching pattern of the lesser occipital nerve. SCM: Sternocleidomastoid muscle; LON: Lesser Occipital nerve; SC: Splenius capitis muscle; LS: Levator scapulae muscle; XI: Accessory nerve; T: Trapezius muscle.

Duplicate: In 21/80 (26\%) specimens, a short distance after the LON emerged, it diverged from the great auricular nerve, dividing into two distinct branches (Type I and Type II) (Fig. 3). Type I ascended on the sternocleidomastoid muscle curving towards the superior third of the ear. Type II was visible on the lateral margin of sternocleidomastoid muscle and innervated the area lateral to the ear (area over mastoid region).

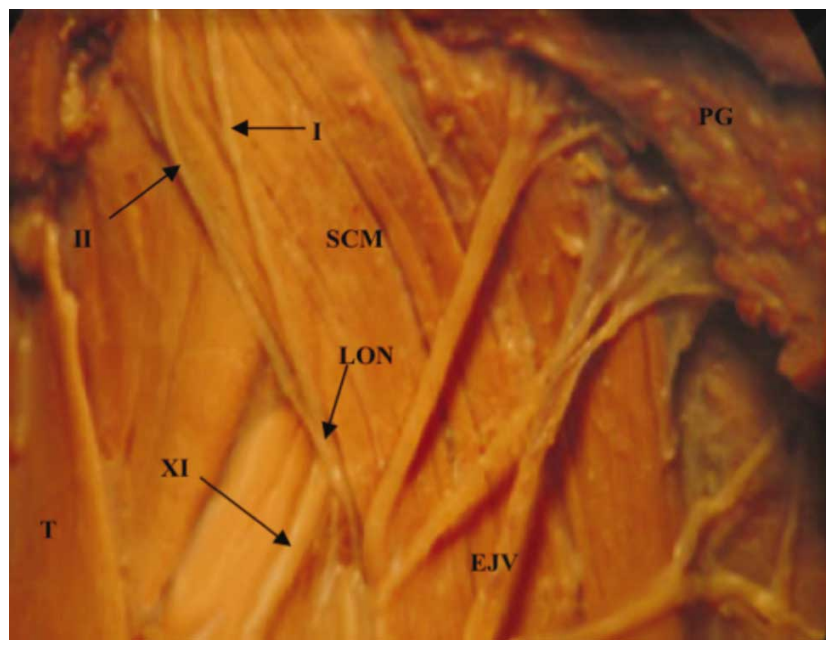

Fig. 3. Right anterior view of the duplication of lesser occipital nerve. I: Type I Lesser Occipital nerve; II: Type II Lesser Occipital nerve; SCM: Sternocleidomastoid muscle; T: Trapezius muscle; PG: Parotid gland; EJV: External jugular vein; LON: Lesser occipital nerve. 
Triplicate: In 3/80 (4\%) of the fetal specimens dissected, the LON emerged from beneath the sternocleiodmastoid muscle as a single trunk, thereafter dividing into three distinct branches that were based on the description by Madhavi and Holla (2004) viz. a) Type I, b) Type II, and c) Type III. a) Type I ascended a short distance on the sternocleidomastoid muscle before dividing into 2 branches viz. Type Ia and Type Ib. Type Ia curved towards the superior part of the ear, and Type $1 \mathrm{~b}$ coursed towards the scalp (lateral occipital region). b) Type II ascended towards the occiput and divided into three smaller branches. c) Type III had a vertical ascent towards the occipital region. It ran parallel to Type II.

In addition, a communicating branch between Type II and Type III was also present (indicated by the dotted circle) (Fig. 4).

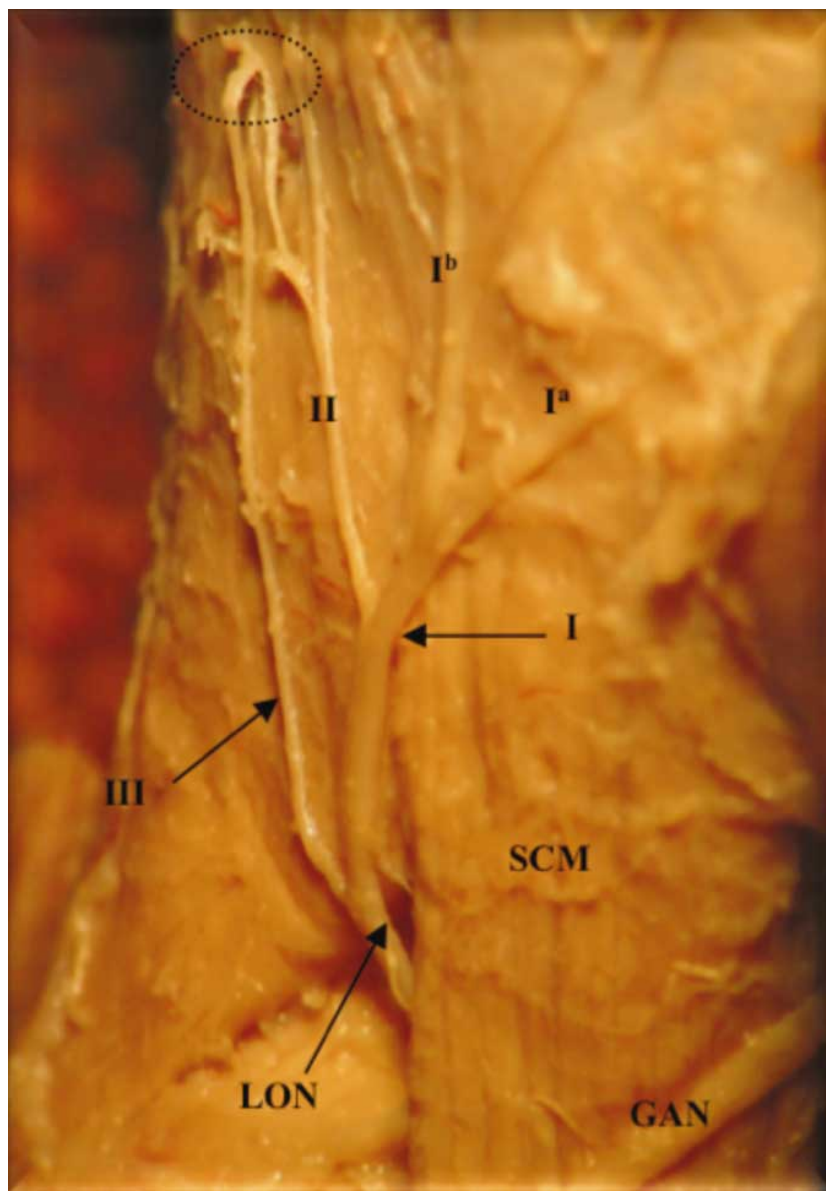

Fig. 4. Right anterior view of the triplication of the lesser occipital nerve. LON: Lesser occipital nerve; I: Type I Lesser Occipital nerve; II: Type II Lesser Occipital nerve; III: Type III Lesser Occipital nerve; SCM: Sternocleidomastoid muscle; GAN: Great auricular nerve; $1 \mathrm{a}$ and $1 \mathrm{~b}$ : Type II Lesser occipital nerve branches;

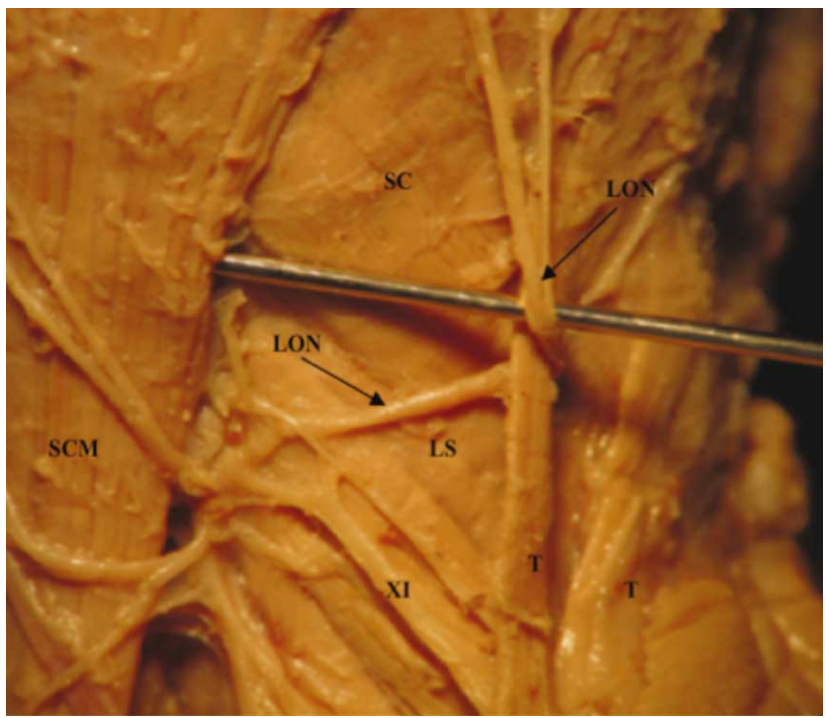

Fig. 5. Left anterior view of the anomalous course of the lesser occipital nerve. LON: Lesser Occipital nerve: SCM: Sternocleidomastoid muscle; XI: Accessory nerve; SC: Splenius capitis muscle; LS: Levator scapulae muscle; T: Trapezius muscle.

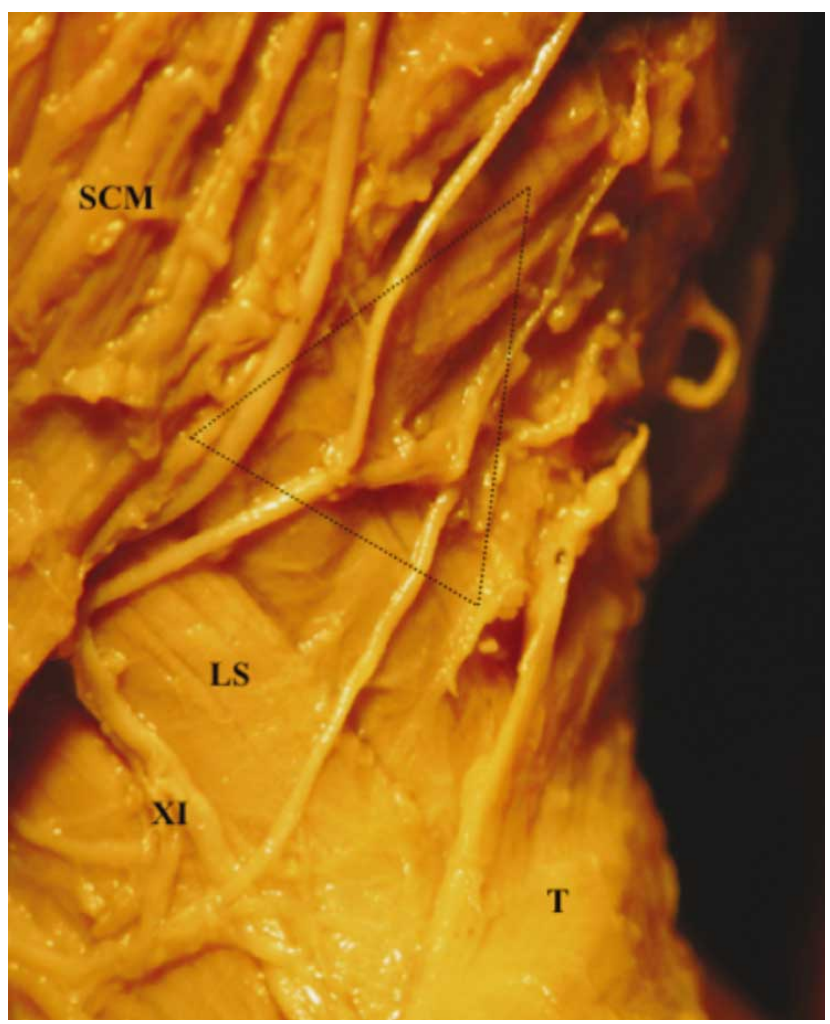

Fig. 6. Left anterior view of the lesser occipital nerve located in "carefree part" of the neck. LON: Lesser Occipital nerve; SCM: Sternocleidomastoid muscle; XI: Accessory nerve; SC: Splenius capitis muscle; LS: Levator scapulae muscle; T: Trapezius muscle. 
d) Variations. In 3/80 (4\%) of the fetuses dissected, the LON emerged from beneath the posterior margin of the sternocleidomastoid muscle, hooked around the accessory nerve, crossed over the levator scapulae muscle in the direction towards the trapezius muscle. A variant trapezius muscle was observed as a thin slip in which the LON hooked around; thereafter the LON divided into 2 branches that crossed the splenius capitus muscle and both branches coursed towards the occipital region (Fig. 5). The accessory nerve crossed the levator scapulae muscle inferior to the LON and pierced the trapezius muscle.

In $2 / 80(2 \%)$ of the fetal specimens, LON was observed in the "carefree part" (defined as the area superior to the accessory nerve) of the neck (indicated by triangle) (Fig. 6). In addition, there was a communication between two of these branches in one specimen.

\section{DISCUSSION}

The LON consistently emerged from beneath the posterior margin of the sternocleidomastoid muscle after it pierced the deep cervical fascia. It was located superior to the great auricular nerve in all specimens, similar to the results obtained by Pantaloni \& Sullivan. In its ascent towards the scalp, mastoid region and superior third of ear, the LON crossed over the levator scapulae and splenius capitis muscles in $85 \%$ of the specimens. In addition, the LON was constantly located in the area around the mastoid process, which was reported to be an area referred to as the "trigger" point of cervicogenic headaches by Fredriksen $e t$ al. (1987) and Lucas et al. In this investigation it was found that the LON was located in this anatomical area; therefore it is possible that the LON may play a role in cervicogenic headaches.

In addition, knowledge of the variable origin of the LONs may assist in the understanding of cervicogenic headaches caused by neck movements. In the majority of the specimens (76\%) the LON arose from the ventral ramus of the second cervical nerve (C2).

The LON displayed single, duplicate and triplicate branching patterns. In the studies conducted by Lucas et al. and Pantaloni \& Sullivan on adult cadavers, duplication of the LON was reported in $(6 / 16 ; 38 \%)$ and $(13 / 19,68 \%)$ of their specimens, respectively. In this study, $3 / 80(4 \%)$ of the fetal specimens depicted triplicate LONs that had a "tree like" appearance. The areas of innervation associated with the single, duplicate and triplicate branches are the posterolateral aspect of the scalp; superior third of the ear and the area over the mastoid region, and the occipital region, respectively.

Of interest, the LON supplied the superior two-thirds of the ear in $12 / 80(15 \%)$ of specimens. It has been suggested that knowledge of this innervation is of importance during facial rejuvenation surgery because inadvertent injury to the LON may result in sensory dysfunction of the ear. Dash et al. (2005) in a study on the LON's involvement with migraine pain relief suggested that due to the LONs variable location, anesthetic blockade may be difficult because of its branching patterns. Therefore, they suggested that an effective location for LON blockage be a "proximal" site, which according to their descriptions is the area below the external auditory canal.

A previously unreported finding which was observed in $3 / 80(4 \%)$ of the fetal specimens related to the course of the LON. It emerged from beneath the posterior margin of the sternocleidomastoid muscle, hooked around the accessory nerve, and crossed over the levator scapulae muscle in the direction towards the trapezius muscle. A variant trapezius muscle was observed as a thin slip around which the LON hooked. This variant LON may become compressed by the trapezius muscle resulting in "entrapment neuropathy" that may cause cervicogenic headaches.

Basmajian \& Slonecker (1989) described the area superior to the accessory nerve within the posterior triangle of neck, where there are no important structures located to as the "carefree part". In 2/80 (2\%) of the fetal specimens, the LON was observed in the "carefree part". It was reported by Lucas et al. that the presence of the LON in the "carefree part" may be a cause of pain in the neck region as well as it playing a vital role in understanding the contribution of this nerve to cervicogenic headaches. In addition, it was suggested that this location may make the nerve vulnerable to compression and stretching leading to cervicogenic headaches.

Knowledge of the anatomy and variations of the origin, course and branching pattern of the LONs may assist in the understanding of cervicogenic headaches. In addition, this knowledge may be of assistance to anesthetists performing regional anesthesia for surgical procedures in the neck region.

PILLAY, P.; PARTAB, P.; LAZARUS, L. \& SATYAPAL, K. S. El nervio occipital menor en fetos. Int. J. Morphol., 30(1):140144, 2012.

RESUMEN: El nervio occipital menor (NOM) es una rama ascendente superficial del plexo cervical que tiene un origen va- 
riable ya sea del ramo ventral del segundo nervio cervical o de los nervios cervicales segundo y tercero, y es solamente sensitivo. Cuarenta fetos (lado derecho: 40/80; izquierdo: 40/80), con edades gestacionales de 15 a 28 semanas fueron microdisecados para documentar la anatomía del NOM. a) Incidencia y morfometría: el NOM estuvo presente en el $100 \%$ de los especímenes, con una longitud media de los lados derecho e izquierdo de 23,59 $\pm 2,32$ $\mathrm{mm}$ y 23,45 $\pm 2,27 \mathrm{~mm}$, respectivamente; b) Curso: en su ascenso hacia la región occipital, el NOM se localiza en el músculo esplenio de la cabeza en el $85 \%$ de las muestras y en el $15 \%$ de las muestras, ascendió verticalmente sobre el músculo esternocleidomastoideo hacia el oído, inervando el tercio superior, c) Patrón de ramificación: el NOM se observa (i) individual: $70 \%$, (ii) duplicado: $26 \%$ y (iii) triplicado: $4 \%$ de los patrones; d) Variación en el curso de NOM se observó en el 6\% de las muestras. El conocimiento de la anatomía y las variaciones del NOM puede ayudar en la comprensión de los dolores de cabeza cervical y puede ser de ayuda a los anestesiólogos a realizar la anestesia regional para procedimientos quirúrgicos en el cuello.

PALABRAS CLAVE: Nervio occipital menor; Rama superficial del plexo cervical; Dolores de cabeza cervicogénico.

\section{REFERENCES}

Basmajian, J, V. \& Slonecker, C. E. Posterior triangle of the neck. In: Grant's method of anatomy. A clinical problem-solving approach. 11th ed. Baltimore, Lippincott Williams and Wilkins, 1989. p.491.

Becser, N.; Bovim, G. \& Sjaastad, O. Extracranial nerves in the posterior part of the head: anatomic variations and their possible clinical significance. Spine, 23:1435-41, 1998.

Berry, M.; Bannister, H. L. \& Standring, S. Nervous System In: William, L. P. (Ed.). Gray's Anatomy. 8th ed. Edinburgh, Churchill Livingstone, 1995. pp.1238-64.

Dash, K. S.; Janis, J. E. \& Guyuron, B. The lesser and third occipital nerves and migraine headaches. Plast. Reconstr. Surg., 115:1752-60, 2005.

Ellis, H. \& Fieldman, S. Anatomy for Anaesthetists Oxford. Blackwell Scientific, 1993.

Fredriksen, T. A.; Hovdal, H. \& Sjaastad, O. "Cervicogenic headache": clinical manifestation. Cephalalgia, 7:147-60, 1987.

Hollingshead, W. H. Anatomy for Surgeons. $3^{\text {rd }}$ ed. Philadelphia, Harper and Row, 1974. p.479.

Lucas, G. D. A.; Laudanna, A.; Choppard, R. P. \& Raffaelli, Jr. E. Anatomy of the lesser occipital nerve in relation to cervicogenic headache. Clin. Anat., 7:90-6, 1994.
Madhavi, C. \& Holla, S. J. Triplication of the lesser occipital nerve. Clin. Anat., 17:667-71, 2004.

Pantaloni, M. \& Sullivan, P. Relevance of the lesser occipital nerve in facial rejuvenation surgery. Plast. Reconstr. Surg., 105:2594603, 2000.

Romanes, G. J. Cunningham's textbook of anatomy. $12^{\text {th }}$ ed. Oxford, Oxford University Press, 1987. p.770-2.

Tubbs, R. S.; Salter, E. G.; Wellons, J. C.; Blount, J. P. \& Oakes, W. J. Landmarks for the identification of the cutaneous nerves of the occipital and nuchal regions. Clin. Anat., 20:235-8, 2007.

Correspondence to:

Professor KS Satyapal

Department of Clinical Anatomy

School of Medical Sciences, Faculty of Health Sciences

Westville Campus, College of Health Sciences

University of KwaZulu-Natal

Private Bag X54001

Durban, 4001

SOUTH AFRICA

Telephone number: + 27312607195

Fax number: + 27312607890

Email address: satyapalk@ukzn.ac.za

Received: 30-08-2011

Accepted: 21-11-2011 